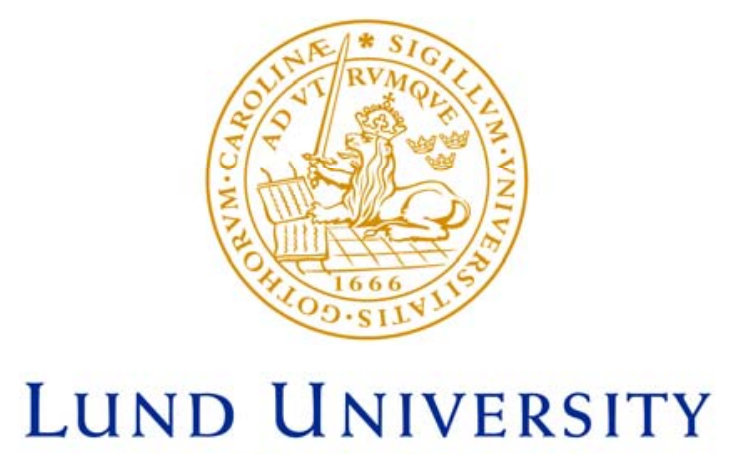

Faculty of Medicine

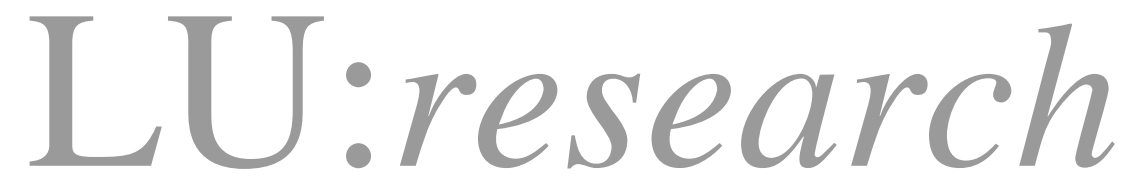

Institutional Repository of Lund University

This is an author produced version of a paper published in American Journal of Physiology. Heart and Circulatory Physiology. This paper has been peer-reviewed but does not include the final publisher proof-corrections or journal pagination.

Citation for the published paper:

Aburawi, Elhadi $\mathrm{H}$ and Berg, Ansgar and Liuba, Petru and Pesonen, Erkki.

"Effects of cardiopulmonary bypass surgery on coronary flow in children assessed with transthoracic Doppler echocardiography"

Am J Physiol Heart Circ Physiol., 2007, Vol: 293, pp. 1138-43.

http://dx.doi.org/10.1152/ajpheart.00025.2007

Access to the published version may require journal subscription. Published with permission from: American Physiological Society 


\title{
Effects of cardiopulmonary bypass surgery on coronary flow in children assessed with transthoracic Doppler echocardiography
}

\author{
Elhadi H. Aburawi, ${ }^{1}$ Ansgar Berg, ${ }^{2}$ Petru Liuba, ${ }^{1}$ and Erkki Pesonen ${ }^{1}$ \\ ${ }^{1}$ Department of Paediatrics, Division of Paediatric Cardiology, Lund University Hospital, \\ Lund, Sweden; and ${ }^{2}$ Institute of Clinical Medicine, Section of Paediatrics, University of \\ Bergen, Bergen, Norway
}

Correspondence and address for reprints to:

Elhadi Aburawi MD, MSc, FRCPI, FRCPCH

Division of Paediatric Cardiology/Department of Paediatrics, Lund University Hospital,

Gettingvägen

SE-221 85 Lund, Sweden.

Tel: +4646178261

Fax: +4646178150

E-mail: elhadi.aburawi@med.lu.se

\section{Grants}

We thank the personnel of Lund University Hospital and the Faculty of Medicine, Lund University for financial support of this study.

\section{Acknowledgment}

We thank Annica Maxedius, registered research nurse, for assistance in patient recruitment, and Dr. Markku Saraste for technical advice in the registrations. 


\begin{abstract}
Perturbation of coronary blood flow (CF) is an important contributor to myocardium-related complications. The study was primarily designed to assess the impact of cardiopulmonary bypass (CPB) surgery on CF by aid of transthoracic Doppler echocardiography. Changes in CF after off-pump coarctation surgery were also studied. All ultrasounds were performed before and $5 \pm 1$ days after surgery. Eighteen children underwent CPB surgery of ventricular left-to-right shunts at the mean age of 6 months, while off-pump surgery (aortic coarctectomy) was undertaken at the mean age of 10 days in 12 children. After CPB surgery, both left anterior descending coronary artery mean diameter and basal CF increased from $1.7 \pm 0.3$ to $2.1 \pm 0.4 \mathrm{~mm}(P=0.001)$ and $27 \pm 10$ to $47 \pm 15 \mathrm{ml} / \mathrm{min}(P=0.0001)$, respectively. These two coronary variables decreased after off-pump coarctectomy: left anterior descending coronary artery mean diameter from $1.8 \pm 0.1$ to $1.7 \pm 0.1 \mathrm{~mm}(P=0.06)$, and CF from $44 \pm 12$ to $25 \pm$ $8 \mathrm{ml} / \mathrm{min}(P=0.001)$. The findings are in keeping with the hypothesis that the previously reported impairment of coronary flow reserve after CPB surgery could be due to increase in basal coronary flow after CPB. Off-pump coarctectomy seems to have little impact on CF, as the postsurgical decline in flow in these patients seems to relate to the reduction in cardiac pressure afterload.

• congenital heart disease $\bullet$ coronary blood flow $\bullet$ cardiopulmonary bypass surgery
\end{abstract}




\section{Introduction}

Perturbation of coronary flow (CF) is an important contributor to myocardium-related complications, such as contractile dysfunction and arrhythmias (1), which sometimes appear during the first week after cardiac surgery on cardiopulmonary bypass (CPB). Coronary flow reserve (CFR) after CPB surgery has been reported to be decreased (2), but the precise pathophysiology remains debatable.

Congenital heart diseases cause several hemodynamic and functional changes that are likely to affect CF. Reduced arterial oxygen saturation, myocardial hypertrophy, increased heart rate, and volume and pressure overload contribute to myocardial oxygen deprivation and CF (3, 4, 5, 6). Oxygen demand regulates coronary flow. The major determinants of the oxygen demand of the myocardium are heart rate, contractility, and wall stress. Wall stress is related to ventricular pressure, chamber diameter, and wall thickness (7). Myocardial oxygen demand is described as rate-pressure product (RPP), the product of heart rate and mean systolic blood pressure (8). The maximal ability of coronary circulation to increase in response to increased cardiac metabolic demand is referred to as CFR. CFR is commonly expressed as the ratio of maximal coronary flow (e.g., by adenosine infusion) to basal flow $(9,10,11)$. CPB, together with cardiac surgery, may affect coronary flow.

Myocardial ischemia-reperfusion leads to coronary endothelial dysfunction due to decreased endothelium-dependent relaxation (12). It has been shown in experimental models that endothelial dysfunction after ischemia-reperfusion persists for at least 4-6 wk $(13,14)$. Moreover, CPB seems to directly affect the arterial smooth muscle cells (15). The aim of this paper was to assess the effects of CPB on the coronary flow in children.

\section{Subjects and methods}




\section{Study Population}

Eighteen infants (mean age $6 \pm 4$ months) referred to our centre for CPB surgery due to ventricular or common atrioventricular septal defect and 12 neonates (mean age $10 \pm 8$ days) with aortic coarctation referred for coarctectomy (off-pump cardiac surgery) were enrolled. The exclusion criteria were as follows: clinical signs of infectious illness or a CRP value before surgery $>0.8 \mathrm{mg} / \mathrm{l}$, heart failure, and preoperative therapy with vasoactive drugs. Transthoracic Doppler echocardiography (TTDE) was performed on all children 1 day preand $5 \pm 1$ days postoperatively. The exclusion criteria were as follows: clinical signs of infectious illness or a CRP value before surgery $>0.8 \mathrm{mg} / \mathrm{l}$, heart failure, and preoperative therapy with vasoactive drugs. For shunt lesion, age-matched controls with no structural heart disease were investigated ( $n=19$, mean age $6.5 \pm 5$ months). For coarctation group, earlier obtained CF data from 55 neonates with mean age of 5 days were used.

Written consent was obtained from the guardians of all children enrolled in the study. The study was approved by the ethics committee for human research at the Lund University.

\section{TTDE}

TTDE examination was performed using Sequoia C512 (Acuson, Mountain View, CA) with 7- to 10-MHz transducer. Standard M- and B-mode and Doppler echocardiographic studies were performed for determining the anatomy and function of the heart. The examination was done by one investigator (EHA).

For CF and flow velocity measurements, the following adjustments were made in the ultrasound device: space time in high frame orate (T1), wall filter was set at two-thirds (F2), the colour gain was adjusted to minimize colour flow signal scatter (gate 3), and colour Doppler mix was on $(16,17)$. Pulsed Doppler of $4.5 \mathrm{MHz}$, sweep rate of $100 \mathrm{~mm} / \mathrm{s}$, and 
velocity range of 15-60 cm/s were used. Measurements were corrected for the angle between the Doppler beam and the coronary flow direction. True velocity was defined as the measured velocity divided by the cosine of the angle between the Doppler beam and the direction of blood.

The bifurcation of the left main coronary artery was imaged from the standard parasternal short-axis view of the great arteries. The internal dimension of the left anterior descending coronary artery (LAD) was measured at the R-wave with the callipers applied to the inner borders. The velocity scale was decreased to the minimum range and then gradually increased until colour signals were optimized within the vessel lumen. After good coronary flow signals were detected, the pulsed Doppler sample volume was placed within the LAD artery $2-3 \mathrm{~mm}$ distal to the bifurcation of the left main coronary artery, and the sample volume was adjusted to $0.5-1.0 \mathrm{~mm}$. A sample volume that gave the best quality envelope and pure sound throughout the cardiac cycle was chosen.

All images were saved on magneto-optic disk and reviewed offline in slow motion and singleframe advance mode for analysis. The diameter of the aortic ring was measured in a long-axis view by M-mode and used for cardiac output calculation. Left ventricular (LV) mass (LVM) was calculated from M-mode in accordance with the American Society of Echocardiography's recommendations (18). LV fractional shortening was computed from the standard formula (19). Arterial blood pressure was measured with an automatic oscillometer cuff sphygmomanometer (Dynamap, Critikon, Tampa, FL). The RPP was calculated by multiplying heart rate with a mean systolic blood pressure (8). The analysis package of the ultrasound unit was used for manual tracing of the spectral envelope. The flow velocity measurements across aortic valve were averaged over three consecutive cardiac cycles, and velocity time integral (VTI) was used for calculating cardiac output. Diastolic peak flow velocity (PFVd), systolic peak flow velocity (PFVs), diastolic VTI (VTId), and systolic VTI 
(VTIs) were measured. The aortic and LAD VTI were used for the calculation of aortic flow and coronary artery flow, respectively. VTI per minute was calculated by multiplying the VTIs + VTId (VTIs+d) with heart rate. Blood flow (CF) per minute was calculated as VTI/minute multiplied with cross-sectional area, where cross-sectional area $=\pi($ coronary diameter $/ 2)^{2}$. The whole equation is as follows: blood flow (CF) $\mathrm{ml} / \mathrm{min}=$ VTIs $+\mathrm{d} \mathrm{x}$ heart rate $\mathrm{x} \pi$ (coronary diameter $/ 2)^{2}$. The myocardial oxygen consumption was calculated from the pressure-work index, which is calculated using an equation that incorporates RPP and LV external work divided by body weight (21).

\section{CPB and Cardioplegia}

Open-heart surgery was performed under mild to moderate hypothermic CPB (body temperature $\left.28-32^{\circ} \mathrm{C}\right)$. For myocardial protection, cold $\left(+4^{\circ} \mathrm{C}\right)$ hyperkalaemic $\left(\mathrm{K}^{+}=0.07\right.$ $\mathrm{mmol} / \mathrm{ml}$ ) blood cardioplegic solution was used. All patients had similar protocol for cardioplegia with anterograde perfusion of the coronary arteries to start with and then retrograde filling through the coronary sinus every 20 min during the CPB.

\section{Postoperative Treatment}

All children after CPB surgery received opioid derivatives in the form of intravenous ketobemidone hydrochloride during the first 2-3 days and then followed by oxicodon orally between 3 and 5 days postoperatively. However, during the postoperative coronary flow studies, these medications had already been stopped. None of our patients was on angiotensin I-converting enzyme inhibitors, lanoxine, phenylepherine, beta-blockers, or any other vasoactive medications, such as nitrate or dopamine, during the intensive care management after day 1 postoperatively. Patients treated by cardiac catheterization were not on any of the above medications. 


\section{Intraobserver Variability}

In 10 children, two registrations of LAD flow velocities were performed 15 min apart by the same observer (EHA). The paired data were analyzed regarding peak flow diastolic and systolic velocities, VTI, and LAD blood flow. The analyses of the Doppler tracings were performed offline.

\section{Statistics}

Paired Student's $t$-test was used for comparison between patient's data before and after surgery. Stepwise multiple regression analysis was used to compare CF with LVM, RPP, and LV fractional shortening. Simple regression analysis was used to calculate the correlation of the changes of CF with diastolic blood pressure changes. All statistical analyses were performed using StatView (SAS Institute 5.0) as a statistical software package. A $P$ value of $<0.05$ was considered statistically significant. Results are presented as means \pm SD. The intraobserver variability was statistically measured according to the British Standards Institution $(21,22)$.

\section{Results}

\section{Infants With Ventricular Left to Right Shunt}

Before surgery. Measurable coronary flow signals in LAD were obtained in 18 of 19 patients. The mean diameter of LAD in patients was $1.7 \pm 0.3 \mathrm{~mm}$, and in their age-matched healthy controls $1.5 \pm 0.2 \mathrm{~mm}$. VTIs $+\mathrm{d}$ was $9 \pm 3$ and $10 \pm 3 \mathrm{~cm}$ and PFVd was $36 \pm 10$ and $37 \pm 5$ 
$\mathrm{cm} / \mathrm{s}$ in patients and controls, respectively. Mean CF in LAD was $27 \pm 10 \mathrm{ml} / \mathrm{min}$ in patients and $17 \pm 5 \mathrm{ml} / \mathrm{min}$ in controls.

After CPB surgery. Mean LVM, LV fractional shortening, cardiac output, RPP, and systolic and diastolic blood pressure were similar before and after surgery. Heart rate was significantly higher before surgery (139 vs. 129 beats/min, $P=0.02$, Table 1 ). CF did not correlate to LVM before or after surgery. It correlated to RPP after surgery $(r=0.5, P<0.04)$, but not before surgery ( $r=0.1, P=0.7$, Figure 1 ). The mean (range) aortic cross clamp time was 59 (33121) min, and CPB time was 98 (64-193) min. There was no correlation between the change in CF before and after surgery and the duration of the CPB. In stepwise multiple-regression analyses, there were no correlations between CF and RPP, LVM, and LV fractional shortening after surgery, and neither was there before surgery.

Myocardial oxygen consumption increased after surgery from $65 \pm 23$ to $71 \pm 27 \mathrm{ml} \mathrm{O}_{2} \cdot \mathrm{min}^{-}$

${ }^{1} \cdot 100 \mathrm{~g}^{-1}(P<0.02)$. There was no correlation between VTId+s or CF and myocardial oxygen consumption. The mean LAD diameter increased from $1.7 \pm 0.3$ to $2.1 \pm 0.4 \mathrm{~mm}(P=0.001)$ with no correlation to CF. LAD VTIs $+\mathrm{d}$ increased from $9 \pm 3$ to $14 \pm 5 \mathrm{~cm}(P=0.05)$, and PFVd from $36 \pm 10$ to $49 \pm 16 \mathrm{~cm} / \mathrm{s}(P<0.05)$. A transthoracic Doppler signal of coronary flow velocity in LAD after surgery with CPB is presented in Figure 2. The CF increased from $27 \pm 10$ to $47 \pm 15 \mathrm{ml} / \mathrm{min}(P=0.0001$, Figure 3$)$. Haemoglobin concentration was higher $5 \pm$ 1 days postoperatively ( $12 \pm 1$ vs. $13 \pm 0.9 \mathrm{~g} / 100 \mathrm{ml}, P<0.0001)$.

\section{Neonates With Coarctation of Aorta}

Before surgery. Coronary flow recording in LAD was successful in all patients with coarctation of aorta. The LAD mean diameter in patients was $1.8 \pm 0.1 \mathrm{~mm}$, and in their agematched controls it was $1.2 \pm 0.1 \mathrm{~mm}$. VTIs $+\mathrm{d}$ was $11 \pm 4$ and $6 \pm 2 \mathrm{~cm}$ and PFVd was $42 \pm$ 14 and $26 \pm 8 \mathrm{~cm} / \mathrm{s}$ in patients and controls, respectively. The LAD mean CF in patients was 
$44 \pm 12 \mathrm{ml} / \mathrm{min}$, and in age-matched neonates $8 \pm 4 \mathrm{ml} / \mathrm{min}$. There was a significant correlation ( $r=0.76, P=0.004$ ) between CF and LVM before, but not after, surgery. After off-pump surgery. Mean LVM, LV fractional shortening, cardiac output, and heart rate before and after surgery were similar. The mean systolic and diastolic blood pressures were significantly lower after surgery: 102 and $80 \mathrm{mmHg}, P=0.0003$, and 55 and $42 \mathrm{mmHg}, P=$ 0.005, respectively. RPP was higher before than after surgery $(P=0.06)$ (Table 2). Before surgery, there was a weak correlation between CF and RPP ( $r=0.53, P=0.1)$, but not at all at 5 days postoperatively ( $r=0.025, P=0.9$ ). In stepwise multiple regressions, there were significant correlations between CF and RPP, LVM, and fractional shortening before ( $r=$ $0.79, P=0.01$ for all), but these disappeared after surgery.

Myocardial oxygen consumption decreased after surgery from $18 \pm 4$ to $15 \pm 3 \mathrm{ml} \mathrm{O}_{2} \cdot \mathrm{min}^{-}$ ${ }^{1} \cdot 100 \mathrm{~g}^{-1}, P<0.001$. There was no correlation between CF and VTId+s and myocardial oxygen consumption. LAD mean diameter was $1.8 \pm 0.1 \mathrm{~mm}$ before surgery and $1.7 \pm 0.1 \mathrm{~mm}$ after surgery $(P=0.06)$. LAD VTIs $+d$ decreased from $11 \pm 4 \mathrm{~cm}$ to $8 \pm 2 \mathrm{~cm}(P<0.05)$, PFVd from $42 \pm 14$ to $30 \pm 10 \mathrm{~cm} / \mathrm{s}(P=0.008)$, and LAD CF from $44 \pm 12$ to $25 \pm 8 \mathrm{ml} / \mathrm{min}$ $(P=0.001$, Figure 4).

\section{Intraobserver Variability}

The following coefficients of variation (COV) were obtained: 4.6\% for LAD's diameter, 11.7\% for PFVd, 7\% for PFVs, 9\% for VTIs and VTId, and 3.3\% for LAD blood flow. The COV for heart rate was $7 \%$.

\section{Discussion}


To our knowledge, this study is the first to study, by aid of TTDE, the CF in relation to CPB surgery. Our study shows that CF in LAD in children with left-to-right shunt is increased for at least 5 days after CPB surgery. The discrepancy between the relatively small increase in myocardial oxygen consumption (from 65 to $71 \mathrm{ml} \mathrm{O}_{2} / \mathrm{min}$ ) and the 2.5-fold increase in coronary flow suggests that other factors are mainly responsible for the postsurgical rise in flow after CPB surgery. Because there is a certain maximal dilatory state that can be reached, it is conceivable to assume that an increase in CF may lead to impaired CFR (23). Therefore, our findings support earlier studies by positron emission tomography (PET) and intracoronary Doppler guide wire (IDGW) showing a drop in CFR after CBP surgery $(2,24)$. In contrast, surgical off-pump correction of aortic coarctation resulted in decrease of both myocardial oxygen consumption and coronary flow, which implies either that off-pump surgery has little or no effect on the coronary flow or that the removal of pressure overload after coarctectomy counteracts possible detrimental effects of off-pump surgery on coronary flow. Importantly, the intraobserver COV for flow velocities and also for flow volume were fairly low, being comparable with earlier reports $(21,25)$.

TTDE is non-invasive, safe, widely available, and inexpensive. TTDE assessment of CF and flow velocity has been shown to correlate well with IDGW, PET, and coronary angiography measurements $(17,26)$. The changes in the diameter of coronary arteries affect CF dramatically, because the area of the coronary artery lumen is related to the artery's radius squared. In the present study, the employed ultrasound probes (7 and $10 \mathrm{MHz}$ ) have an axial resolution of $0.1 \mathrm{~mm}$, thus rendering the comparison in diameter measurements accurate. Measurements of coronary artery diameter by transthoracic echocardiography correlate well with measurements with quantitative coronary angiography $(27,28)$. In healthy children (4-53 mo of age), there is a linear correlation of LAD's CF and PFVd with LVM (29). During the first month of life, the PFVd, VTIs+d, and CF in LAD increase. These 
changes are related to the rapid body growth during this period of life. The physiological improvement in LV relaxation and compliance that occur during the first month of life could be an explanatory factor for the increase in coronary flow parameters with age (30, 31, 32). In our study, flow measurements in the LAD in age-matched normal controls were used as normal values for coronary flow (25).

The hypertrophic myocardium due to coarctation implies increased oxygen demand and blood flow.

After coarctectomy, with subsequent decrease in cardiac pressure afterload, the LAD diameter, VTId+s, PFVd, and CF all decreased, but they were still higher on day 5 than in control neonates. The increase in CF before surgery in coarctation patients is related to coarctation-induced elevation in blood pressure, which leads to high myocardial oxygen demand and consequent increase of coronary flow. The CF decreases after coarctectomy, as expected, because of diminished cardiac pressure afterload due to decreased myocardial oxygen demand.

The postoperative decrease of CF along with the normalization of myocardial oxygen demand per unit of myocardial tissue result in increase of CFR in these patients (33).

During the immediate postoperative period, there are factors affecting coronary flow, such as an inflammatory response. Inflammation is associated with several factors with adverse influence on arterial endothelial and smooth muscle cells. Complement system is activated, proinflammatory cytokines are released and oxidative stress and disturbances in calcium homeostasis lead to ischemia-reperfusion(34). Christen and colleagues (35) suggested that hemolysis was the main cause of early oxidative stress. TNF- $\alpha$ upregulates inducible nitric oxide (NO) synthase activity with secondary increased release of NO, thereby contributing to the reduction in the intrinsic tone of coronary microcirculation (36). Intense upregulation of inducible NO synthase leads to high levels of intravascular NO, which can damage endothelial 
cells through its oxidative potential (34). Prolonged ischemia-reperfusion causes an increase in oxygen-derived free radicals such as superoxide anions. Superoxide reacts with NO, forming peroxynitrate, which is highly damaging for endothelial cells $(37,38)$. CPB with cardioplegic arrest results in vasomotor dysfunction (39, 40, 23).

Previous studies by PET in neonates and infants operated with CPB have shown low CFR values $(2,41)$. As suggested by the present study, one possible explanation could reside in the increased basal coronary flow at 5 days after CPB surgery. In controls, CBF was $17 \mathrm{ml} / \mathrm{min}$, assuming a normal CFR of $\sim 4$, the maximal obtainable coronary flow in the patients would be $68 \mathrm{ml} / \mathrm{min}$, and we measured $47 \mathrm{ml} / \mathrm{min}$. Our findings suggest that use of CPB during cardiac surgery and the type of congenital heart disease are important factors affecting the postoperative resting $\mathrm{CF}$ in children. It has been reported that, in patients with transposition of great arteries after arterial switch operation, the coronary flow as assessed by IDGW is increased and CFR is decreased, even 5 yr after surgery (42). This could be due to surgical technique per se, but eventual long-lasting effects of CPB surgery cannot be ruled out.

\section{Study Limitations}

Intravenous adenosine infusion to measure CFR could not be done, because the consents from the parents were not obtained. Longer postoperative follow up would have been indicated, but this could not be done, as the patients were discharged by day 7-8 after surgery. In conclusion, coronary flow is increased after CPB surgery, a finding that could explain, in part, the previously reported decrease of CFR. Off-pump surgery as such, at least in children with aortic coarctation, seems to have little or no impact on coronary flow as the postsurgical decline in flow in this category of patients relates to the reduction in cardiac pressure afterload. TTDE renders possible serial coronary flow studies in children after cardiac surgery. 


\section{References}

1. Hassanabad ZF, Furman BL, Parratt JR, Aughey E. Coronary endothelial dysfunction increases the severity of ischaemia-induced ventricular arrhythmias in rat isolated perfused hearts. Basic Res Cardiol 93: 241-249, 1998.

2. Donnelly JP, Raffel DM, Shulkin BL, Corbett JR, Bove EL, Mosca RS, Kulik TJ. Resting coronary flow and coronary flow reserve in human infants after repair or palliation of congenital heart defects as measured by positron emission tomography. $\mathrm{J}$ Thorac Cardiovasc Surg 115: 103-110, 1998.

3. Fogel MA, Rychik J, Vetter J, Donofrio MT, Jacobs M. Effect of volume unloading surgery on coronary flow dynamics in patients with aortic atresia. J Thorac Cardiovasc Surg 113: 718-726, 1997.

4. Hofstetter R, Zeike B, Messmer BJ, von Bernuth G. Echocardiographic evaluation of systolic left ventricular function in infants with critical aortic stenosis before and after valvotomy. Thorac Cardiovasc Surg 38: 236-240, 1990.

5. Hongo M, Goto T, Watanabe N, Nakatsuka T, Tanaka M, Kinoshita O, Yamada H, Okubo S, Sekiguchi M. Relation of phasic coronary flow velocity profile to clinical and hemodynamic characteristics of patients with aortic valve disease. Circulation 88: 53-60, 1993.

6. Kangos JJ, Ferrer MI, Francios RA, Blanc WA, Blumenthal S. Electrocardiographic changes associated with papillary muscle infarction in congenital heart disease. Am J Cardiol 23: 801-809, 1969.

7. Graham TP Jr, Covell JW, Sonnenblick EH, Ross J Jr, Braunwald E. Control of myocardial oxygen consumption: relative influence of contractile state and tension development. J Clin Invest 47: 375-385, 1968. 
8. Baller D, Bretschneider HJ, Hellige G. A critical look at currently used indirect indices of myocardial oxygen consumption. Basic Res Cardiol 76: 163-181, 1981.

9. Coffman JD, Gregg DE. Reactive hyperemia characteristics of the myocardium. Am J Physiol 11: 1143-1149, 1960.

10. Hoffman JIE. Pediatric cardiovascular intensive care: myocardial perfusion. Prog Pediatr Cardiol 4: 117-123, 1995.

11. Hoffman JIE. Maximal coronary flow and the concept of coronary vascular reserve. Circulation 70: 153-159, 1984.

12. Ku DD. Coronary vascular reactivity after acute myocardial ischemia. Science 218: 576-578, 1982.

13. Kaeffer N, Richard V, Francois A, Lallemand F, Henry JP, Thuillez C. Preconditioning prevents chronic reperfusion induced coronary endothelial dysfunction in rats. Am J Physiol Heart Circ Physiol 271: H842-H849, 1996.

14. Pearson Schaff HV, Vanhoutte PM. Long-term impairment of endothelium-dependent relaxations to aggregating platelets following reperfusion injury in canine coronary arteries. Circ Res 8: 1921-1927, 1990.

15. Wang SY, Friedman M, Franklin A, Sellke FW. Myogenic reactivity of coronary resistance arteries after cardiopulmonary bypass and hyperkalemic cardioplegia. Circulation 2: 1590-1596, 1995.

16. Hozumi T, Yoshida K, Ogata Y, Akasaka T, Asami Y, Takagi T, Morioka S. Noninvasive assessment of significant left anterior descending coronary artery stenosis by coronary flow velocity reserve with transthoracic color Doppler echocardiography. Circulation 97: 1557-1562, 1998.

17. Saraste M, Koskenvuo J, Knuuti J, Toikka J, Laine H, Niemi P, Sakuma H, Hartiala J. Coronary flow reserve: measurement with transthoracic Doppler echocardiography is 
reproducible and comparable with positron emission tomography. Clin Physiol 21: 114-122, 2001.

18. Schiller NB, Shah PM, Crawford M, DeMaria A, Devereux R, Feigenbaum H, Gutgesell H, Reichek N, Sahn D, Schnittger I, et al. Recommendations for quantification of the left ventricle by two-dimensional echocardiography. American Society of Echocardiography Committee on Standards, Subcommittee on Quantitation of Two-Dimensional Echocardiograms. J Am Soc Echocardiogr 2: 358-367, 1989.

19. Lewis RP, Sandler H. Relationship between changes in the left ventricular dimension and ejection fraction in man. Circulation 44: 548-557, 1971.

20. Rooke GA, Feigl EO. Work as a correlate of canine left ventricular oxygen concentration, and the problem of catecholamine oxygen wasting. Circ Res 50: 27386, 1982.

21. British Standards Institution. Precision of Test Methods. I. Guide for the Determination and Reproducibility for a Standard Test Method. London: British Standards Institution, 1979, no. 5479.

22. Hanseus K, Bjorkhem G, Lundstrom NR. Cardiac function in healthy infants and children: Doppler echocardiographic evaluation. Pediatr Cardiol 15: 211-218, 1994.

23. Sellke FW, Shafique T, Ely DL, Weintraub RM. Coronary endothelial injury after cardiopulmonary bypass and ischemic cardioplegia is mediated by oxygen-derived free radicals. Circulation 88: 395-400, 1993.

24. Harada K, Aoki M, Toyono M, Tamura M. Coronary flow velocity and coronary flow velocity reserve in children with ventricular septal defect. Tohoku J Exp Med 202: 7785, 2004.

25. Oskarsson G, Pesonen E. Coronary blood flow in healthy neonates: effects of left ventricular function and mass. Pediatr Cardiol 25: 11-16, 2004. 
26. Hozumi T, Yoshida K, Akasaka T, Asami Y, Ogata Y, Takagi T, Kaji S, Kawamoto T, Ueda Y, Morioka S. Noninvasive assessment of coronary flow velocity and coronary flow velocity reserve in the left anterior descending coronary artery by Doppler echocardiography: comparison with invasive technique. J Am Coll Cardiol 32: 12511259, 1998.

27. Kiviniemi TO, Saraste M, Koskenvuo JW, Airaksinen KE, Toikka JO, Saraste A, Parkka JP, Hartiala JJ. Coronary artery diameter can be assessed reliably with transthoracic echocardiography. Am J Physiol Heart Circ Physiol 286: H1515-H1520, 2004.

28. Kurotobi S, Nagai T, Kawakami N, Sano T. Coronary diameter in normal infants, children and patients with Kawasaki disease. Pediatr Int 44: 1-4, 2002.

29. Oskarsson G, Pesonen E. Flow dynamics in the left anterior descending coronary artery in infants with idiopathic dilated cardiomyopathy. Am J Cardiol 90: 557-561, 2002.

30. Kozak-Barany A, Jokinen E, Rantonen T, Saraste M, Tuominen J, Jalonen J, Valimaki I. Efficiency of left ventricular diastolic function increases in healthy full-term infants during the first months of life. A prospective follow-up study. Early Hum Dev 57: 4959, 2000.

31. Czernin J, Muller P, Chan S, Brunken RC, Porenta G, Krivokapich J, Chen K, Chan A, Phelps ME, Schelbert HR. Influence of age and haemodynamics on myocardial blood flow and flow reserve. Circulation 88: 62-69, 1993.

32. Yasuoka K, Harada K, Tamura M, Takada G. Left anterior descending coronary artery flow and its relation to age in children. J Am Soc Echocardiogr 15: 69-75, 2002.

33. Vassalli G, Hess OM. Measurement of coronary flow reserve and its role in patient care. Basic Res Cardiol 23: 339-353, 1998. 
34. Sellke FW, Boyle EM Jr, Verrier ED. Endothelial cell injury in cardiovascular surgery: the pathophysiology of vasomotor dysfunction. Ann Thorac Surg 62: 1222 1228, 1996.

35. Christen S, Finckh B, Lykkesfeldt J, Gessler P, Frese-Schaper M, Nielsen P, Schmid ER, Schmitt B. Oxidative stress precedes peak systemic inflammatory response in pediatric patients undergoing cardiopulmonary bypass operation. Free Radic Biol Med 38: 1323-1332, 2005.

36. Lamas S, Michel T, Brenner BM, Marsden PA. Nitric oxide synthesis in endothelial cells: evidence for a pathway inducible by TNF-alpha. Am J Physiol Cell Physiol 261: C634-C641, 1991.

37. Grygelewski RJ, Palmer RMJ, Moncada S. Superoxide anion is involved in the breakdown of endothelium-derived relaxing factor. Nature 320: 454-460, 1986.

38. Rubanyi GM, Vanhoutte PM. Superoxide anions and hyperoxia inactivate endothelium-derived relaxing factor. Am J Physiol Heart Circ Physiol 250: H822H827, 1986.

39. Khan TA, Bianchi C, Ruel M, Voisine P, Li J, Liddicoat JR, Sellke FW. Mitogenactivated protein kinase inhibitor and cardioplegia-cardiopulmonary bypass reduce coronary myogenic tone. Circulation 108: 348-353, 2003.

40. Sellke FW, Friedman M, Dai HB, Shafique T, Schoen FJ, Weintraub RM, Johnson RG. Mechanism causing coronary microvascular dysfunction following crystalloid cardioplegia and reperfusion. Cardiovasc Res 27: 1925-1932, 1993.

41. Yates RW, Marsden PK, Badawi RD, Cronin CF, Anderson DR, Tynan MJ, Maisey MN, Baker EJ. Evaluation of myocardial perfusion using positron emission tomography in infants following a neonatal arterial switch operation. Pediatr Cardiol 21: 1-8, 2000. 
42. Gagliardi MG, Adorisio R, Crea F, Versacci P, Di Donato R, Sanders SP. Abnormal vasomotor function of the epicardial coronary arteries in children five to eight years after arterial switch operation: an angiographic and intracoronary Doppler flow wire study. J Am Coll Cardiol 46: 1565-1567, 2005. 
Table 1. Hemodynamic and echocardiographic data before and $5 \pm 1$ days after surgery with $\mathrm{CPB}$ in patients with shunt and controls

$$
\begin{gathered}
\text { Patients }(n=18) \\
\text { Controls }(n=19) \quad \text { Presurgery } \quad \text { Postsurgery }
\end{gathered}
$$

Age (range), mo

Systolic BP, mmHg

Diastolic BP, mmHg

$\mathrm{HR}$, beats/min

$\mathrm{RPP}, \mathrm{mmHg} / \mathrm{min}$

$\mathrm{CO}, \mathrm{ml} \cdot \mathrm{min}^{-1} \cdot \mathrm{kg}^{-1}$

FS, \%

LVM, g

Aortic cross clamp time, min

CPB duration, min

$\mathrm{Hb}, \mathrm{g} \%$

LAD diameter, mm

LAD VTId+s, cm

LAD PFVd, cm/s

$\mathrm{LAD} \mathrm{BF}, \mathrm{ml} / \mathrm{min}$

$$
\begin{gathered}
6.5(3-16) \\
89(7) \\
50(6) \\
132(10) \\
11,940(1,690) \\
446(133) \\
38(4) \\
21(5.6)
\end{gathered}
$$

$1.5(0.2)$
$10(3)$
$37(5)$
$17(5)$

$6(3-18)$
$95(10.0)$
$53(8.0)$
$139(15)$
$13,278(1,127)$
$422(222)$
$46(9)$
$25(10)$

(2)

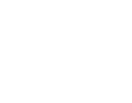
6 (3-18)

$98(5.0) \quad 0.46$

$54(8.0) \quad 0.9$

$129(17) \quad 0.02$

$12,672(1,050) \quad 0.25$

423 (191.3) $\quad 0.9$

$42(9) \quad 0.6$

25 (10)

0.9

$58.9(23.5$

98.8 (30.6)

$12(1) \quad 13(0.9) \quad 0.0001$

$1.7(0.3) \quad 2.1(0.4) \quad 0.001$

9 (3.0)

$14(5.0) \quad 0.05$

$36(10) \quad 49(16) \quad 0.05$

$27(10)$

0.0001

\footnotetext{
Values are means (SD); $n$, no. of subjects. BP, blood pressure; HR, heart rate; RPP, rate pressure product; CO, cardiac output; FS, fractional shortening; LVM, left ventricular mass; $\mathrm{CPB}$, cardiopulmonary bypass; LAD, left anterior descending artery; VTId+s, velocity time integral in diastole and systole; PFVd, diastolic peak flow velocity; BF, blood flow. $P$ values are for presurgery vs. postsurgery.
} 
Table 2. Hemodynamic and echocardiographic data in patients with coarctation of aorta before and $5 \pm 1$ days after non-CPB surgery and in controls

\begin{tabular}{lcccc}
\hline & & \multicolumn{2}{c}{ Patients $(n=12)$} & \\
\cline { 3 - 4 } & Controls $^{*}(n=55)$ & Presurgery & Postsurgery & $P$ \\
\hline Age (range), days & $5(0.5-30)$ & $10(2-50)$ & $10(2-50)$ & \\
Systolic BP, mmHg & $79(12)$ & $102(11)$ & $80(7.0)$ & 0.0003 \\
Diastolic BP, mmHg & $43(10)$ & $55(8.0)$ & $42(4.0)$ & 0.005 \\
RPP, mmHg/min & $9,724(2,042)$ & $14,302(1,310)$ & $12,045(1,298)$ & 0.06 \\
HR, beats/min & $123(17)$ & $148(6.5)$ & $147(10.6)$ & 0.8 \\
CO, ml·min ${ }^{-1} \cdot \mathrm{kg}^{-1}$ & & $390(121)$ & $410(130)$ & 0.2 \\
FS, \% & $39(5.1)$ & $47(10.2)$ & $46(9.5)$ & 0.6 \\
LVM, g & $12(3)$ & $14(5.5)$ & $14(5.5)$ & \\
LAD diameter, mm & $1.2(0.1)$ & $1.8(0.1)$ & $1.7(0.1)$ & 0.06 \\
LAD VTId+s, cm & $6(2.0)$ & $11(4)$ & $8(2)$ & 0.05 \\
LAD PFVd, cm/s & $26(8.0)$ & $42(14)$ & $30(10)$ & 0.008 \\
LAD BF, ml/min & $8(4.0)$ & $44(12)$ & $25 \pm 8$ & 0.001 \\
& & & &
\end{tabular}

Values are means (SD); $n$, no. of subjects. $P$ values are for presurgery vs. postsurgery.

* From Ref. 25. 
Legends to the figures

Fig. 1. Blood flow (BF) in left anterior descending coronary artery (LAD) correlates with the rate-pressure product after cardiopulmonary bypass (CPB) surgery $(r=0.5, P<0.04)$.

Fig. 2. Pulsed-wave Doppler profile of coronary velocity signal in LAD after surgery with CPB.

Fig. 3. BF in LAD before and after CPB surgery. The bars indicate $90 \%$ confidence intervals about the median.

Fig. 4. BF in LAD before and after coarctectomy (off-pump surgery). The bars indicate $90 \%$ confidence intervals about the median. 
Fig. 1

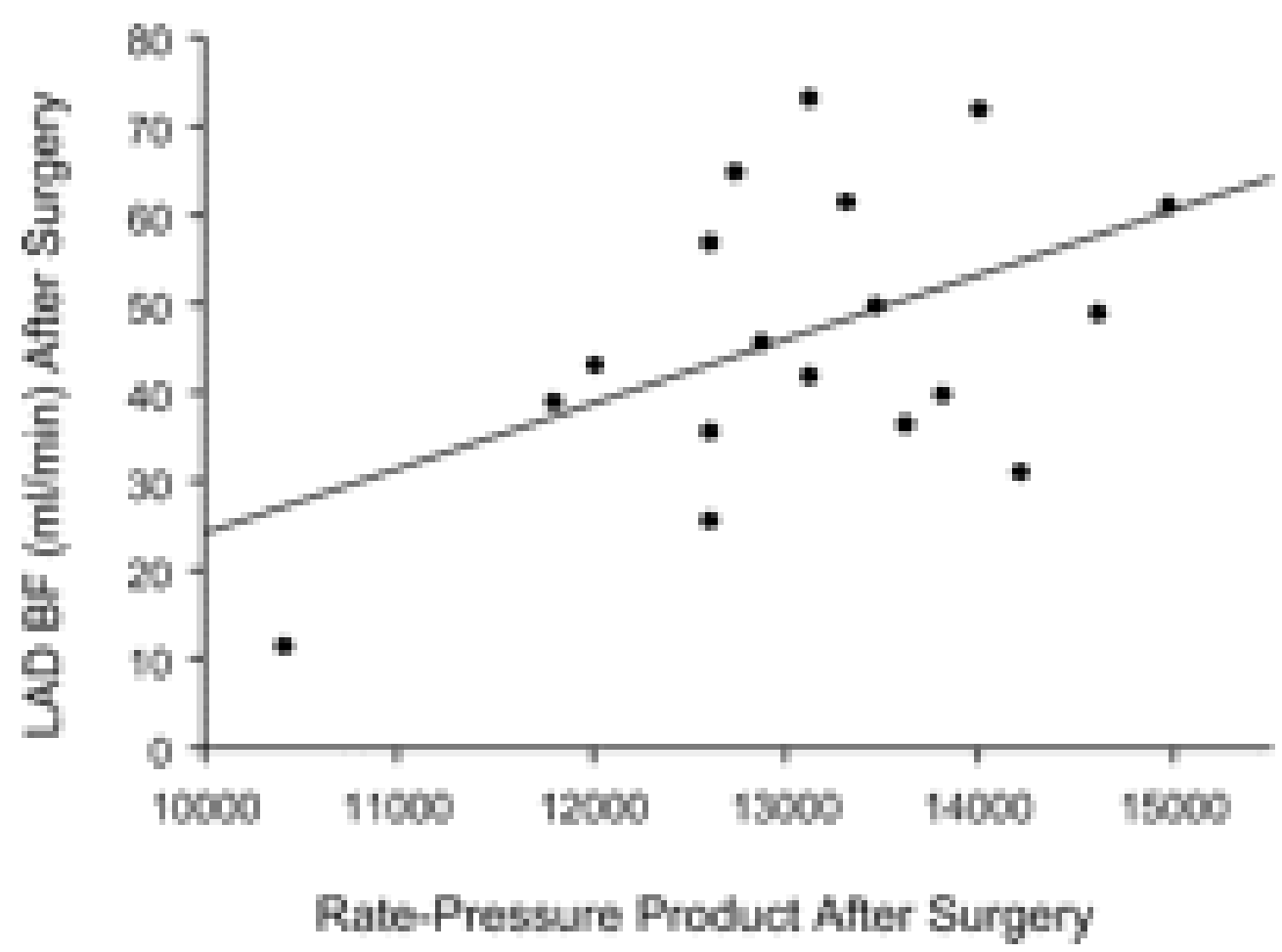

Fig. 2

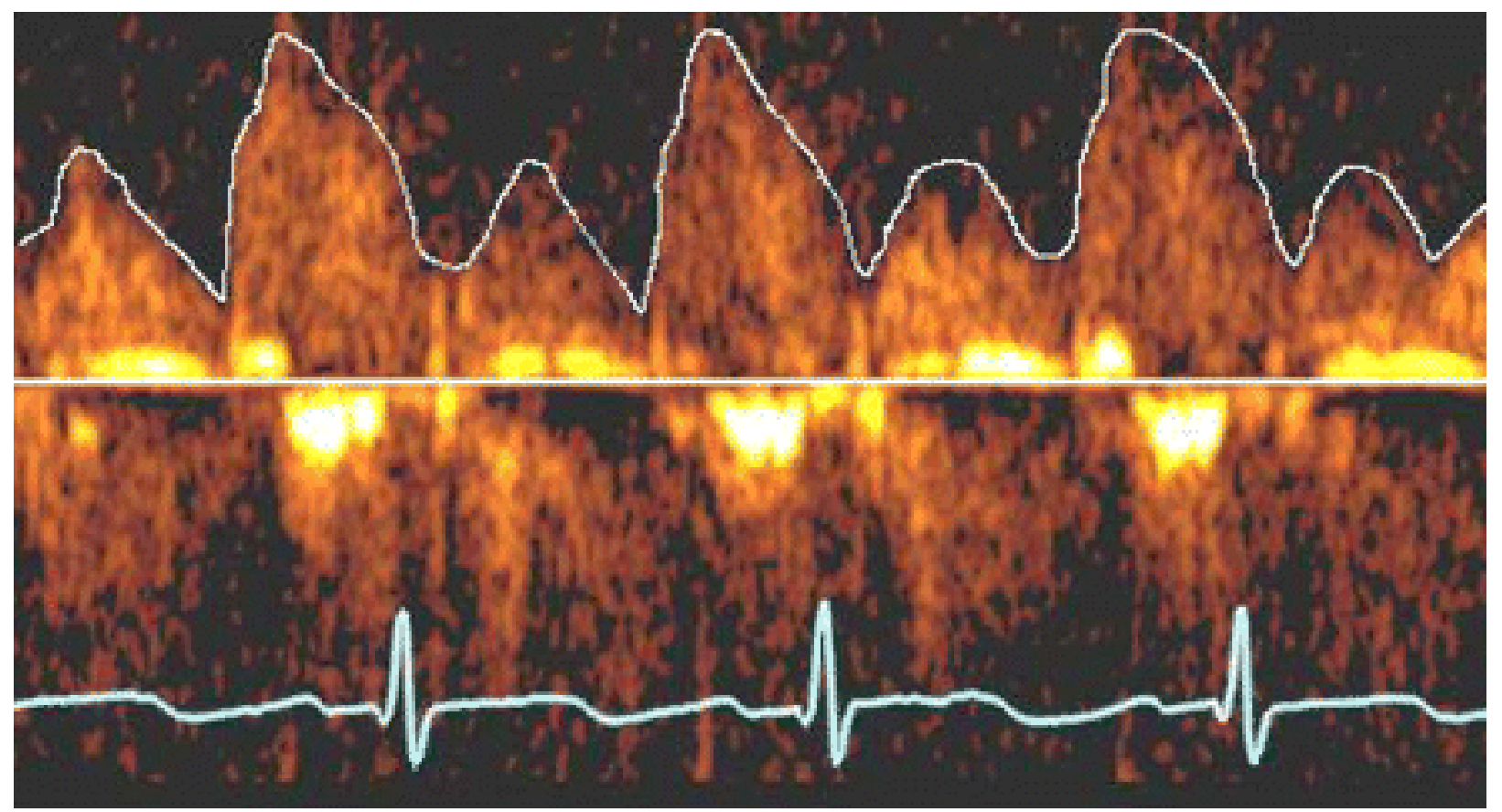


Fig. 3

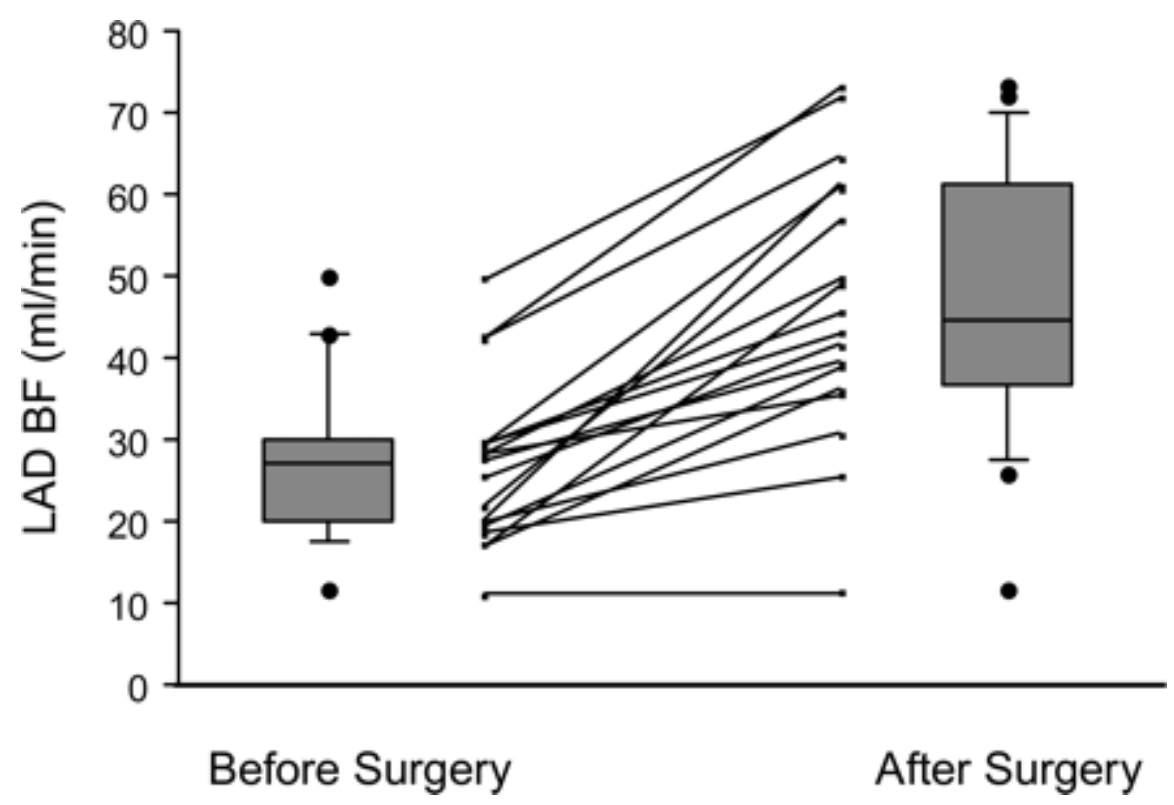

Fig. 4

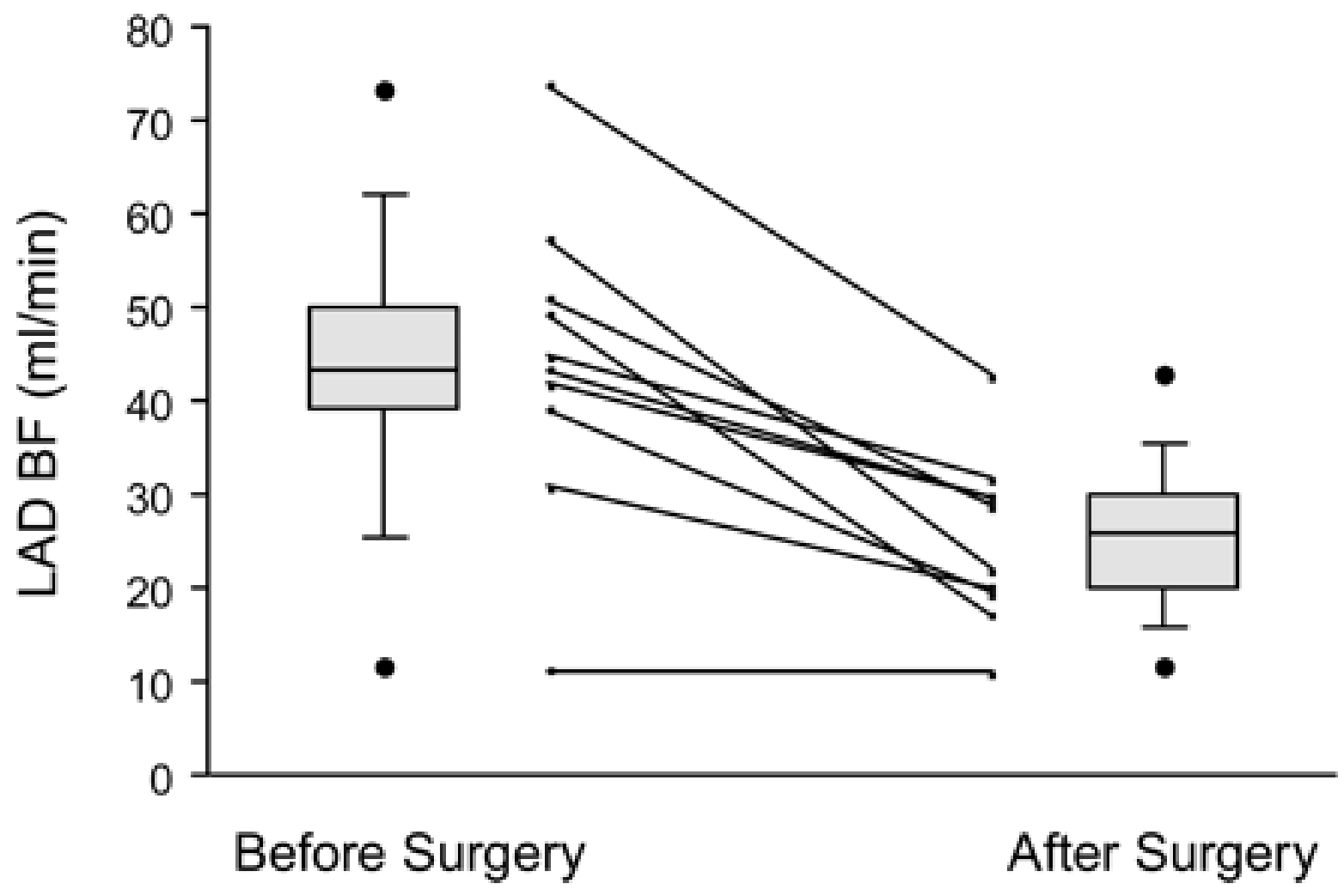

